\title{
PKM Pelatihan Tari Kreasi pada Siswa-Siswi Kelas 2 SMA Negeri 8 Gowa
}

\author{
Nurlina Syahrir ${ }^{1}$, Johar Linda ${ }^{2}$, Rahma $^{3}$ \\ 1,2,3 Jurusan Seni Pertunjukan, Fakultas Seni dan Desain, Universitas Negeri Makassar
}

\begin{abstract}
The ability of second grade students of SMA NEGERI 8 GOWA in dance lessons, especially creative dance, is still below standard. This is ofcourse an obstacle in demonstrating these creative dances, and also an obstacle in the development of regional creation dances.Therefore, a creative dance training was held for the 2nd grade students of SMA NEGERI 8 GOWA. the implementation of the training aims to improve the skills and knowledge of students in demonstrating creative dances, especially the Pa'duppa dance. Creative dance training uses the method of lecturing on theory and demonstration in practice, while the steps taken are: 1 . The preparatory stage includes site observation; a. Site observation, b. Processing permission letter, c. Determine the training schedule, 2. Implementation includes, a. Provides material theory / introduction to creative dance, b. Giving practice material, c. Evaluation. Training is carried out to cover the shortcomings, weaknesses, and demands of an institution or school, due to the lack of talent and interest of students in the field of dance, if there are talented people, most of them are below standartd. After the implementation of creative dance training, students are expected to be able to demonstrate and develope and create dances that have been taught and make a traditional culture to be proud of. However, it should be noted that each ethnic group in South Sulawesi has a different cultural background, which in the development of traditional culture, it is necessary to pay attention to these differences, so as not to become a misunderstanding.
\end{abstract}

Keywords: Training, Dance, Creation, Pa'duppa

\section{PENDAHULUAN}

Kemampuan bergerak atau menari merupakan keterampilan yang telah umum dimiliki oleh anakanak, baik anak-anak usia sekolah dasar, maupun siswa SMP, bahkan banyak siswa SMA yang telah memiliki keterampilan bergerak dan menari dengan gerak yang lebih kreatif. Dalam hal ini bisa dilihat dengan maraknya kegiatan lomba tari diberbagai event.

Kemampuan atau keterampilan siswa dalam bergerak atau menari, bukan hanya didukung oleh daya ingat masing-masing individu, akan tetapi seharusnya didukung oleh tehnik dan bentuk tubuh yang benar. Akan tetapi, fenomena yang terjadi sekarang ini, siswa hanya handal dalam bergerak pada tarian yang diajarkan oleh guru di kelas saja, itupun sebatas mengandalkan daya ingat dalam menghafal gerak tari yang diajarkan. Sedangkan tehnik dalam bergerak masih jauh dari sempurna. Oleh karena itu, dibutuhkan pelatihan tari kreasi untuk membantu pembelajaran di kelas praktek tari, agar setiap siswa dapat mengikuti bentuk tari yang diajarkan oleh guru dengan tehnik gerak yang baik dan benar.

Keterampilan bergerak di atas panggung seiring dengan istilah bahwa apabila seseorang sudah bisa bergerak di atas panggung, maka dikatakanlah bahwa dia seorang penari. Hal tersebut menunjukkan bahwa setiap manusia bisa memiliki kemampuan untuk menari, hanya saja ada orang tertentu yang mengasah kemampuannya terus menerus, namun adapula yang membiarkannya begitu saja sampai akhirnya potensi yang dimiliki jadi hilang. Maka untuk meningkatkan kemampuan bergerak, khususnya seni tari maka seorang tidak perlu terbatasi oleh sekat-sekat keilmuan yang ada. Teruslah belajar, banyak melihat, dan banyak latihan. Oleh karena itu, banyaklah menonton pertunjukan dan sering mengapresiasi suatu pementasan. Apabila sudah bisa mengapresiasi dan melihat kelebihan maupun kekurangan dari unsurunsur tari dalam suatu pertunjukan, maka sesungguhnya secara tidak langsung anda telah belajar menari.

Unsur-unsur dalam seni tari yang perlu diperhatikan oleh siswa atau penari yaitu wiraga 
(penguasaan tekhnik gerak atau keterampilan dalam bergerak, wirasa (penghayatan gerak atau gerak dengan rasa yang tepat), dan wirama (keserasian antara gerak dan iringan musik). Oleh karena itu, untuk menerapkan hal tersebut, maka dalam mempelajari tari bentuk dan tari kreasi, sekiranya dapat mengetahui dan menguasai tehnik dasar gerak yang semestinya, dan bukan sekedar bergerak sesuai dengan kemauannya. Sementara itu diharapkan agar siswa dapat bergerak sesuai dengan bentuk gerak yang baik dan benar. Meskipun materi gerak tari berasal dari gerak tari tradisional perlu pula memperagakan gerak dengan tehnik yang benar sebagai langkah awal pembelajaran dibidang seni tari dengan penguasaan pada gerak, dan rasa. Akan tetapi, waktu dalam proses belajar mengajar praktek di dalam kelas tidak memungkinkan untuk melakukan pembenahan gerak satu persatu siswa-siswi secara berulang-ulang karena waktu yang sangat terbatas.

Siswa-siswi kelas 2 SMA Negeri 8 Gowa tidak mempelajari pelajaran seni tari, untuk mata pelajaran seni budaya, yang dipelajari adalah seni musik. Oleh karena itu siswa-siswi kelas 2 sangat membutuhkan bimbingan dan pelatihan tari sebagai keseimbangan pelajaran seni musik dan seni tari. Maka dari itu, kami tertarik untuk melaksanakan pelatihan tari kreasi pada siswa-siswi kelas 2 SMA Negeri 8 Gowa. Kegiatan ini diharapkan menambah keterampilan siswa-siswi dalam mengikuti mata pelajaran tari sesuai dengan tehnik gerak yang diajarkan oleh guru. Selain itu, diharapkan pula menjadi pedoman atau dasar untuk pembelajaran tari dari daerah lain. Kegiatan tersebut diharapkan pula bisa berlanjut pada siswasiswi di kelas lain. Selain itu kegiatan ini diharapkan pula dapat bernilai ibadah dan bisa membekali keterampilan, dan wawasan yang lebih memadai terhadap seluruh peserta pelatihan yang ikut terlibat.

Berhubung karena situasi dan kondisi, adanya masa pandemi Covid-19, maka pelatihan tari kreasi mengalami hambatan, oleh karena waktu pertemuan yang sangat terbatas, akan tetapi dengan semangat anak-anak untuk latihan, maka pelatihan melalui media (daring) tetap berjalan meski tidak maksimal. Oleh karena itu, untuk memperoleh hasil yang maksimal, maka diadakan pelatihan secara luring, dengan tetap memperhatikan protokol kesehatan, yaitu, dengan memakai masker, jaga jarak, dan selalu mencuci tangan, serta menghindari bersalaman.

Hasil identifikasi awal menunjukkan bahwa permasalahan utama mitra adalah:

1. Terdapat beberapa siswa yang belum memahami tentang tari secara umum, belum mengetahui apa itu tari kreasi, dan tidak memahami perbedaan tari tradisional dan tari modern.

2. Terdapat beberapa siswa yang melakukan gerak tari dengan hafalan tanpa menggunakan tehnik gerak yang benar, karena siswa hanya bergerak tanpa memperhatikan tehnik gerakannya.

3. Ada siswa yang memiliki tubuh yang kurang lentur atau masih kaku dalam melakukan gerak tari, namun memiliki minat dan bakat yang tinggi untuk belajar praktek tari serta daya ingat (hafalan) yang cukup bagus.

\section{METODE YANG DIGUNAKAN}

Pelaksanaan kegiatan pelatihan dalam bentuk pemberian materi utama adalah pemberian materi teori tentang elemen-elemen yang berhubungan dengan tari, dan yang berhubungan dengan tubuh manusia, dilanjutkan dengan pembelajaran praktek tari dengan menggunakan iringan musik. Pemberian pelatihan tari kreasi berupa tehnik menggerakan badan, tehnik menggerakan tangan dan gerak kaki dengan cara demonstrasi. Dan diakhir pertemuan diberikan evaluasi untuk mengukur kemampuan peserta dalam bentuk praktek secara individu dan secara berkelompok. Setiap individu dapat bergerak secara lentur sehingga dapat mengikuti tehnik gerak yang benar dari pengajar mata pelajaran dari pelatihan tersebut.

Metode yang digunakan dalam pemberian pelatihan atau training bersifat teoritis (ceramah) dan praktek (demonstrasi) yang meliputi: proses pembelajaran yakni pemberian materi teori sebagai 
pengantar, dan praktek/demostrasi tari kreasi, serta penggunaan media dan literatur yang relevan, selanjutnya dilakukan evalusi. Untuk mencapai tujuan yang dimaksudkan di atas maka langkahlangkah yang ditempuh meliputi: a. Tahap persiapan, meliputi, observasi lokasi, $b$, Mengurus surat izin, dan c. Menentukan jadwal pelaksanaan. Setelah pelaksanaan pelatihan tari kreasi siswasiswi SMA Negeri 8 Gowa diharapkan mampu mengaplikasikan secara teoritis dan demonstrasi, baik secara berkelompok maupun secara individu.

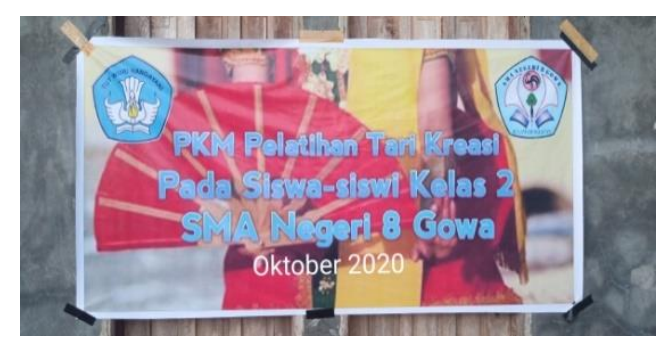

Gambar 1. Foto spanduk pelaksanaan kegiatan PKM

\section{PELAKSANAAN DAN HASIL KEGIATAN}

Materi kegiatan pelatihan tari kreasi Sulawesi Selatan meliputi teori dan praktek. Materi teori tari menjelaskan tentang arti tari secara umum, dan gerak tari Paduppa. Gerak tari yang diajarkan adalah tari Paduppa versi Anida, yang judul aslinya adalah tari Marellau Pammase Dewata dalam buku Tari Kreasi Baru Sulawesi Selatan, yang di tulis oleh Ny Andi Nurhani Sapada. Tarian ini mengandung sifat sakral (suci) serta merupakan perpaduan antara kebiasaan lama (kepercayaan lama) yang masih terdapat di daerah-daerah pedalaman Sulawesi Selatan dengan agama. (1995: 17) Tari Paduppa sangat cocok diajarkan kepada anak-anak usia sekolah karena hanya terdiri dari empat ragam dan gerakannya mudah untuk dipahami. Keempat ragam tersebut adalah sebagai berikut.

1. Ragam Satu

a. Penari melangkah ke depan melangkah tiga langkah sambil jinjit kemudian berdiri, kaki kanan diseret membuat setengan lingkaran, kedua tangan diputar di samping badan, tangan kanan memegang tempat dupa, tangan kiri memegang sarung (kingking lipa).

b. Gerakan diulang 3 kali

c. Berputar membuat lingkaran lalu melakukan gerakan yang sama satu kali

d. Dilanjutkan gerak kedua

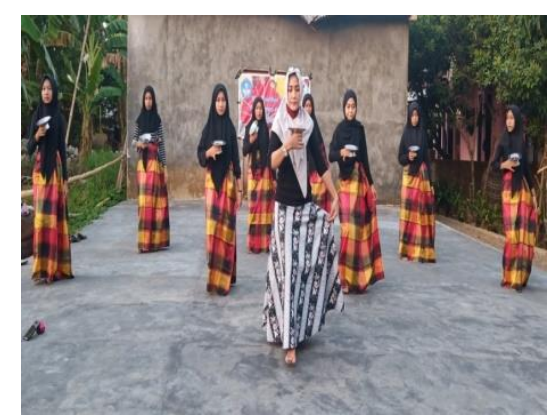

Gambar 2. Gerak ragam ke 1

2. Ragam Dua

a. Melangkah ke depan satu kali, lalu duduk berlutut rendah, properti disimpan/ditaruh di depan (di lantai), kemudia tangan kanan di tarik ke depan dada dengan posisi awal.

b. Tangan kiri di tarik kedepan sejajar dengan tanganh kanan lalu diputar, kemudia diayun ke samping kiri arah belakang lalu diputar.

c. Tangan kiri diayun ke depan lalu diputar dan di ayun ke atas diulang dua kali, tangan kanan tetap di depan dada (posisi awal).

d. Kedua tangan diayun ke samping badan, tangan kanan diayun ke depan dada, disusul oleh tangan kiri lalu diayun ke samping kanan kemudian diputar. Kembali ke samping badan.

e. Kedua tangan diayun ke samping badan, tangan kanan diayun ke depan dada, lalu tangan kanan mengambil properti, dilanjutkan dengan gerakan berdiri.

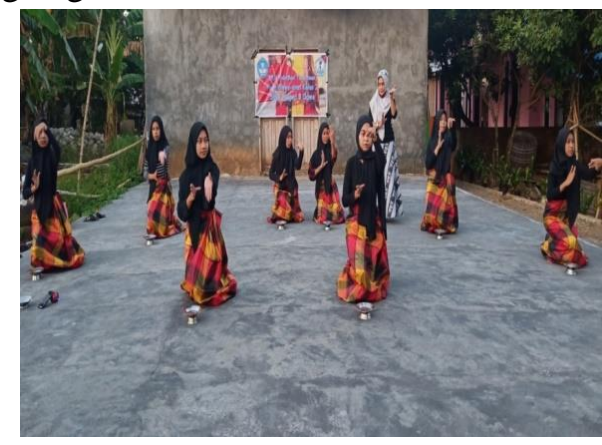

Gambar 3. Gerak ragam 2 
3. Ragam Tiga

a. Penari melakukan gerak ke tiga sambil melangkah ke depan properti berpindah ke tangan kiri, lalu tangan kanan diayun ke samping kanan lurus, lalu diputar.

b. Kemudian melakukan gerakan menabur empat mata angin, (tangan kanan mengambil kembang (isi properti) lalu menaburkan ke depan, dan ke samping kanan.

c. Kemudian terakhir menghadap ke depan melakukan gerakan ragam satu.

d. Putar panjang membuat komposisi.

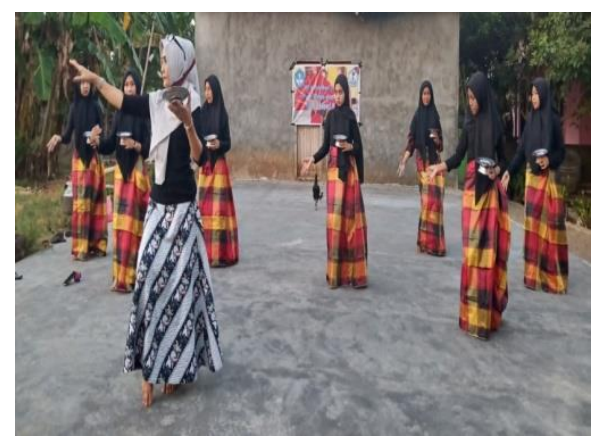

Gambar 4. Gerak ragam 3

4. Ragam Empat

a. Penari melangkah satu langkah ke depan, lalu duduk menaruh properti di depan (lantai), lalu tangan kiri diayun ke atas dan diputar dekat telinga sambil berdiri.

b. Melakukan gerakan melangkah ke kiri dua kali, lalu mundur dua kali posisi tangan di depan dada, tangan kiri di samping kiri (posisi awal), dilanjutkan melangkah ke samping kanan dengan diikuti kedua tangan diayun dan diputar, lalu mundur dan langsung duduk dengan gerakan tangan kanan diayun kesamping kanan, lalu tangan kiri diayun ke saping kiri, lalu diayun ke samping kiri atas lalu diputar, kemudian mengambil properti, dan berdiri,

c. Gerakan diulang 2 kali dengan posisi yang sama.

d. Terakhir mengulang gerak pertama, lalu penari keluar dari panggung (exit).

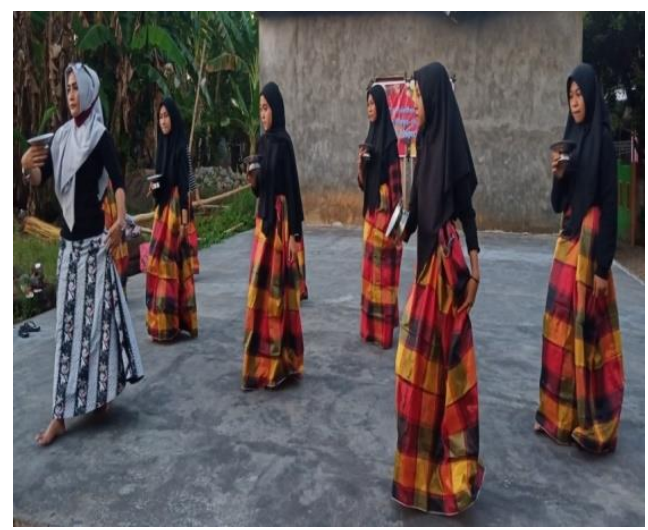

Gambar 5. Ragam gerak ke 4

\section{KESIMPULAN}

Berdasarkan hasil evaluasi kegiatan PKM dalam "Pelatihan Tari Kreasi Sulawesi Selatan pada siswa-siswi kelas 2 SMA 8 Gowa", maka dapat disimpulkan bahwa:

1. Dalam pelatihan tersebut sebagian besar peserta mampu memahami dan mendemonstrasikan gerak tari kreasi (paduppa) yang terdiri dari empat ragam, dengan baik dan benar berkat adanya bimbingan dari pada instruktur dan pengajar yang terdiri dari dosen Seni Tari dan mahasiswa FSD UNM.

2. Hasil dalam pelatihan ini, peserta menyatakan memperoleh manfaat, terutama mengetahui tentang tari kreasi yang ada di Sulawesi Selatan, dan bagaimana memperagakan gerak tari paduppa dengan tehnik gerak yang baik dan benar.

\section{UCAPAN TERIMA KASIH}

Penulis menyadari bahwa dalam penulisan laporan ini masih terdapat kekurangan, baik keterbatasan waktu, maupun materi. Namun kegiatan workshop ini dapat terlaksana sesuai dengan harapan penulis. Dan artikel Pengabdian pada Masyarakat dapat terselesaikan juga tepat waktu, tidak lepas dari bantuan beberapa pihak. Oleh karena itu diucapkan banyak terima kasih atas bantuan dana PNBP Universitas Negeri Makassar, tahun 2013, kontrak 460/UN36.11/LP2M/2020, 
tanggal 13 Mei 2020. Tentunya tidak lupa pula penulis hanturkan terima kasih dan penghargaan setinggi-tingginya kepada, Rektor Universitas Negeri Makassar, Ketua Lembaga Penelitian dan Pengabdian kepada Masyarakat beserta staff, Dekan Fakultas Seni dan Desain UNM, Pembantu Dekan I FSD UNM, Ketua Program Studi Seni Tari FSD UNM, Kepala SMA Negeri 8 Gowa ,Guru Seni Budaya SMA Negeri 8 Gowa Akhirnya penulis mengucapkan terima kasih kepada siapa saja yang telah memberikan bantuan untuk terwujudnya artikel ini. Kesempurnaan artikel tentunya membutuhkan koreksi dan saran, sehingga dapat menjadi sempurna dan bermanfaat bagi kita semua, Amin

\section{DAFTAR PUSTAKA}

Hadi, Sumandiyo. 2007. Kajian Tari Teks dan Konteks, Yogyakarta: FSP ISI Yogyakarta.

Jazuli, 2008. Paradigma Kontekstual Pendidikan Seni, Semarang: Unesa University Press.

Meri, La 1986. Dances Composition, the Basic Elements, (Elemen-elemen dasar Komposisi Tari), terj. Soedarsono, Yogyakarta: Lagaligo ISI,

Murgiono, Sal, 1983. Koreografi, Jakarta: Departemen Pendidikan dan Kebudayaan.

Nadjamuddin, Munasiah, 1982. Tari Tradisional Sulawesi Selatan, Ujung Pandang: Berita Utama Bakti Baru.

Sapada, Andi Nurhani, 1993. Tari Kreasi baru Sulawesi Selatan Cetakan II, Ujung Pandang: PT. Sarana Panca Karya. , 1996. Pelajaran Dasar Tari Sulawesi Selatan, Ujung Pandang: CV. Anggun.

Soedarsono, 2002. Seni Pertunjukan Indonesia di Era Globalisasi, Yogyakarta: Gadjah Mada University Press.

Tim Abdi Guru, 2005. Kesenian untuk SMP, Jakarta: Erlangga. 